\title{
O MARXISMO HISTORICISTA NA FORMAÇÃO DE PROFESSORES DE EDUCAÇÃO DE JOVENS E ADULTOS (EJA): TEORIA E PRÁTICA
}

\author{
Fábio Fernandes Vilella ${ }^{1}$
}

\section{Resumo}

A formação de professores, na perspectiva do marxismo historicista, foi abordada em diversos trabalhos ao longo de nossa trajetória acadêmica (2009; 2010-2012 e 2013-2015). No sentido de aprofundar a questão da formação de professores, analisaremos, neste texto, as possibilidades de superação da divisão do trabalho na escola através do trabalho coletivo, elemento fundamental para a organização do trabalho pedagógico e da didática. Para tal finalidade, abordaremos alguns elementos da formação dos bolsistas do Programa Unesp de Educação de Jovens e Adultos (Peja) de São José do Rio Preto (SP), em 2013-2014, que têm em perspectiva a didática para a pedagogia histórico-crítica desenvolvida por Gasparin (2013) e elaborada a partir de Saviani (1999), com vistas a discutir as inter-relações entre a crítica à divisão do trabalho na escola e à inteligência coletiva, tendo como cenário os usos das novas tecnologias aplicadas à educação. Ao elaboramos a crítica à divisão do trabalho na escola, emerge a temática da gestão democrática na escola, especialmente na Educação de Jovens, Adultos e Idosos (EJA).

Palavras-chave: Formação de Professores; Pedagogia Histórico-Crítica; Educação de Jovens, Adultos e Idosos.

\begin{abstract}
Teacher education, in historicist marxist perspective, was addressed in several papers throughout our academic career (VILELLA, 2009; 2010-2012, and 2013-2015). In order to further the issue of teacher training, we will analyze in this text, the possibilities of overcoming the division of labor in school through the collective work, a key element for the organization of educational work and teaching. For this purpose, we discuss some elements of the training of fellows Unesp Program Youth and Adult Education (Peja), São José do Rio Preto (SP), in 2013 to 2014, which have in the didactic perspective to the historical-critical pedagogy developed by Gasparin (2013) and elaborated from Saviani (1999), in order to discuss the interrelationships between critical division of labor in school and collective intelligence, against the backdrop of the uses of new technologies in education. To elaborate the critique of the division of labor in school, emerges the theme of democratic management in school, especially in the Education of Young, Adults and Seniors (EJA).
\end{abstract}

Keywords: Teacher Education; Historical-Critical Pedagogy; Education of Youth, Adults and Seniors.

\footnotetext{
${ }^{1}$ Doutor e mestre em direito previdenciário pela Pontifícia Universidade de São Paulo. Professor-assistente do programa de doutorado da Pontifícia Universidade Católica de São Paulo.
} 


\section{INTRODUÇÃO}

A formação de professores, na perspectiva do marxismo historicista, foi abordada em diversos trabalhos ao longo de nossa trajetória acadêmica (VILELLA, 2009; 2010-2012 e 2013-2015). No sentido de aprofundar a questão da formação de professores, analisaremos, neste texto, as possibilidades de superação da divisão do trabalho na escola através do trabalho coletivo, elemento fundamental para a organização do trabalho pedagógico e da didática. As páginas, a seguir, deste texto, estão organizados da seguinte maneira: (1) alguns aspectos teóricos da formação de professores na perspectiva do marxismo historicista; (2) aspectos práticos da formação de professores; (3) considerações finais; (4) referências e (5) notas.

\section{ALGUNS ASPECTOS TEÓRICOS DA FORMAÇÃO DE PROFESSORES NA PERSPECTIVA DO MARXISMO HISTORICISTA}

A formação de professores, na perspectiva do marxismo historicista, pressupõe a contribuição de diversos autores. Para Löwy (2009, p. 146), o marxismo historicista é uma corrente metodológica no seio do pensamento marxista que se distingue pela importância central atribuída à historicidade, dialeticamente concebida, dos fatos sociais e pela disposição em aplicar o materialismo histórico a si mesma. Tem com representantes dessa corrente Lukács (1966), Korsch (1964), Gramsci (2004; 2000) e Goldmann (1966). Para Löwy $(2009$, p. 146) a corrente historicista do marxismo produziu as ideias mais férteis e mais profundas para uma solução dialética, escapando assim tanto às armadilhas do "princípio da carruagem" (Cf. (Löwy, 2009, p. 112). A principal fraqueza, a tentação reducionista, entre o condicionamento social do pensamento e a autonomia da prática científica.

A questão dos intelectuais em Gramsci articula-se com o conjunto total de sua obra e, segundo Macciocchi (1977, p. 186), trata-se do "único aspecto de seu pensamento que se impõe objetivamente a todos". Em Gramsci [1926 (2004)], encontra-se a categoria "bloco histórico", como conceito que estabelece o vínculo orgânico entre estrutura e a superestrutura ideológica e política. A definição do papel dos intelectuais no "bloco histórico" foi estudada pela primeira vez por Gramsci no ensaio "A Questão Meridional", no qual caracteriza os intelectuais como o elemento que "cimenta" a estrutura econômica e as superestruturas do bloco agrário do Mezzogiorno italiano. Segundo Portelli (1990), "bloco histórico" é um conceito-chave do pensamento de Gramsci que gravita em torno da questão dos intelectuais.

Do ponto de vista dos intelectuais e sua inserção no "bloco histórico", Gramsci (2000) afirma que os intelectuais são os responsáveis pela elaboração da ideologia dominante, dando-lhes consciência dos seus próprios papéis e transformando as suas ideologias em concepções de mundo de toda a sociedade. Eles são os responsáveis pelas funções de hegemonia social e do governo político. Para exercer essa hegemonia, eles se utilizam dos chamados Aparelhos de Hegemonia de Estado (doravante, AHE), tais como: a

\begin{tabular}{|l|l|l|l|l|}
\hline Q Povista Dialectus & Ano 2 & n. 6 & Janeiro - Agosto 2015 & p. 163-176 \\
\hline
\end{tabular}


escola, a igreja, a imprensa, etc. Os intelectuais utilizam os AHE para difundir determinadas concepções de mundo e obter o consenso da sociedade. A partir das relações entre "bloco histórico", "intelectuais" e os "AHE", Gramsci (2000) revela a divisão do trabalho entre os intelectuais:

É verdade que a própria função organizativa da hegemonia social e do domínio estatal dá lugar a certa divisão do trabalho e, portanto, toda uma gradação de qualificações. A atividade intelectual deve ser diferenciada, inclusive, do ponto de vista intrínseco; estes graus, nos momentos de extrema oposição, dão lugar a uma verdadeira e real diferença qualitativa: no mais alto grau, devem ser colocados os criadores das várias ciências, da filosofia, da arte etc., no mais baixo, os "administradores" e divulgadores mais modestos da riqueza intelectual já existente, tradicional, acumulada. (GRAMSCI, 2000, p. 21).

No trecho destacado de Gramsci (2000, p. 20-22), emerge a divisão do trabalho entre os intelectuais e sua hierarquização na sociedade capitalista. Essa hierarquização possui função estratégica, tendo em vista a construção da "hegemonia social". Gramsci (2000) mostra a importância dos intelectuais e seus papéis de educadores e dirigentes dentro da sociedade capitalista. São essas contradições que se constituem em condições objetivas para um futuro processo de transformação da sociedade e da superação da divisão do trabalho.

Recolocando na alça de mira a temática proposta, diversos pesquisadores têm abordado as relações entre o trabalho docente, a divisão do trabalho contemporâneo e a educação. Dentre eles podemos destacar, em ordem alfabética: Antunes (2007); Apple (1995); Barbosa (2009); Bruno (2005); Carvalho (1989); Cury (1995); Dal Rosso (2008); Enguita (1993); Esteve (1999); Freitas (2011), Gorz et al. (1996); Hirata (1989); Hypolito (1997); Jáen (1991); Lima (2001); Oliveira (2004); Silva (2005); Torres Santomé (2003), entre outros.

Retomando a obra de Carvalho (1989), inauguradora de uma abordagem inovadora, a autora aponta para a necessidade de articular a formação do educador à questão da divisão do trabalho na escola. Carvalho (1989) demonstra que os estudos e debates sobre a temática têm-se polarizado em duas perspectivas críticas que se desdobram até os dias de hoje: a primeira tem como ponto de partida o papel ideológico que os especialistas de educação têm cumprido até agora, reproduzindo no âmbito escolar a divisão social do trabalho. Propõe a extinção dos referidos especialistas da escola, como forma de superação entre os que pensam (especialistas) e os que executam a educação (professores) e, consequentemente, a democratização do processo de trabalho. A segunda perspectiva apresenta o mesmo ponto de partida e de chegada, mas difere quanto à forma de resolução do problema, propondo resgatar a função progressista que essas mesmas especializações portam e colocá-las, assim, a serviço da transformação social. Nossa abordagem propõe uma terceira perspectiva: a do desaparecimento progressivo da divisão capitalista do trabalho na escola (aufhebung/superação/reestruturação radical). Partimos da seguinte afirmação de Mészáros (2002, p. 1054):

Assim, dar plena ênfase à necessária fragmentação do trabalho sob as condições da divisão tradicional do trabalho equivale, ao mesmo tempo, a reconhecer o espaço deixado ao exercício das funções tradicionais do Estado durante todo um período histórico; quer dizer, enquanto a fragmentação do trabalho não for efetivamente superada - tanto em termos materiais quanto em termos ideológicos e políticos - através da 'negação' real

\begin{tabular}{|c|c|c|c|c|}
\hline Q Ronista Dialectus & Ano 2 & n. 6 & Janeiro - Agosto 2015 & p. $163-176$ \\
\hline
\end{tabular}


(aufhebung/superação/reestruturação radical) da divisão social do trabalho há muito estabelecida. (MÉSZÁROS, 2002, p. 1054)

Retomamos ainda a proposta de Enguita (1993, p. 208), segundo o qual haveria um isomorfismo entre relações sociais na educação e relações sociais no processo de trabalho e de intercâmbio. Estamos diante da fragmentação do trabalho docente sob as condições da divisão tradicional do trabalho. Quanto à divisão do trabalho, na fábrica capitalista, a divisão entre trabalho manual e trabalho intelectual manifesta-se pela distinção entre o trabalho de produção imediata designada aos operários e o trabalho de engenheiros e técnicos que dirigem o processo de produção ao tomar as decisões no que diz respeito às mudanças a serem feitas no processo de trabalho, nas máquinas empregadas, nas regras técnicas, etc. Quando essa divisão do trabalho é mantida ou se desenvolve, especialmente nas escolas, coloca os produtores imediatos, isto é, os professores, numa posição subordinada em relação aos especialistas.

O trabalho docente, conforme aponta Machado (2004), é objeto de muitas críticas por parte dos professores, especialistas e alunos. Para a autora, três fatores encontram-se diretamente vinculados a esse problema, cuja raiz é a própria forma de organização escolar: $1^{\circ}$ ) o estudo sem exame crítico da realidade atual, $2^{\circ}$ ) a fragmentação disciplinar, $3^{\circ}$ ) as relações de poder instituídas. Um aspecto que cabe destacar é a fragmentação disciplinar, onde o saber aparece fragmentado em disciplinas que ficam sob a responsabilidade de diversos professores, que as apresentam como se elas possuíssem um fim em si mesmo. Os conteúdos se autonomizam em relação ao conjunto do saber escolar, por isso, são tratados desarticuladamente, dificultando a compreensão do aluno, que se apropria de pedaços de conhecimentos dessa e daquela disciplina, gerando desinteresses que se traduzem em atitudes de apatia ou revolta e desordem. Segundo Machado (2004, p. 104), a escola precisa corresponder aos interesses e expectativas dos que nela atuam, e ter estreita ligação com a vida:

Esses interesses precisam ser considerados no projeto político-pedagógico, cuja essência deve ser a formação humana a partir de uma visão dinâmica e global do conhecimento. Isso significa a elaboração de um currículo escolar que leve à superação da fragmentação metodológica e da alienação, tendo por base a relação educação-trabalho, o exame crítico da realidade, a interdisciplinaridade e a organização científica do trabalho, cujo pressuposto é o método dialético. Em síntese, a forma escolar da sociedade democrática deve propiciar a formação omnilateral, valorizando todas as dimensões e potencialidades do sujeito com vistas ao seu pleno desenvolvimento, que inclui a abordagem da solidariedade como um valor subjetivo (emoções, representações) e objetivo (trabalho social produtivo). (MACHADO, 2004, p. 104).

Conforme teoriza Mészáros (2002, p 1061), a maior dificuldade é vislumbrar a superação da fragmentação e da divisão do trabalho sem reduzir os problemas em jogo num apelo à "consciência de classe idealizada". Mészáros (2002, p. 1061) afirma que se deve apelar para uma crescente "consciência social totalizante", evocando-se ao mesmo tempo as "mediações materiais necessárias" que visam a superação da fragmentação do trabalho e pelas quais torna-se inicialmente possível o desenvolvimento desta consciência.

A "fragmentação do trabalho", demonstra Mészáros (2002, p. 1062), não pode ser eliminada pela "socialização da produção" capitalista conforme as experiências históricas dos países da "transição socialista". Nem pode ser superada, em vista das estruturas materiais profundamente arraigadas da divisão do trabalho, durante um longo tempo após a

\begin{tabular}{|l|l|l|l|l|}
\hline Genista Dialectus & Ano 2 & n. 6 & Janeiro - Agosto 2015 & p. 163-176 \\
\hline
\end{tabular}


revolução política socialista, isto é, durante a etapa da "Transição Socialista". Mészáros (2002, p. 1062) mostra que as "mediações materiais", caracterizadas por uma capacidade vital para promover a redução progressiva do papel restritivo das determinações materiais herdadas, devem ser as estruturas reguladoras da vida social durante todo o período da "transição socialista". Segundo nosso ponto de vista, a experiência chinesa da revolução cultural, de 1966 a 1976, apresenta as "mediações materiais” necessárias em questão.

A crítica à divisão do trabalho na escola possui condições de construção de novas relações, ao incorporar comparativamente as experiências dos chamados países do "terceiro mundo", especialmente o período da experiência chinesa da revolução cultural. Em outro trabalho, procuramos revelar as possíveis relações entre a organização do trabalho pedagógico das "escolas no campo" desenvolvido pelos intelectuais orgânicos do Instituto Superior Politécnico "José Antonio Echeverría", La Habana, Cuba, entre 19601975 (Cf. VILELLA, 2009). A experiência chinesa da revolução cultural coloca as práticas educativas em outro patamar, especialmente as da crítica da divisão do trabalho na escola.

Trata-se da sistematização de experiências na educação comparada que possuem "afinidades eletivas". O conceito de "afinidade eletiva" deve ser entendido a partir de Löwy (1989), que traçou uma arqueologia da intelectualidade judaica, voltada aos movimentos políticos de esquerda e concentrada nos domínios da Mitteleuropa, composta por Benjamin, Lukács, Fromm, Scholem, Buber, Kafka, Lowentahl, Heine, Marx, Freud, etc. Conforme Löwy (1989, p. 18), trata-se de um conceito que:

[...] permite justificar processos de interação que não dependem nem da causalidade direta, nem da relação 'expressiva' entre forma e conteúdo (por exemplo, a forma religiosa como 'expressão' de um conteúdo político e social). Sem querer substituir-se aos outros paradigmas analíticos, explicativos e compreensivos, ele pode constituir um ângulo de abordagem novo, até aqui pouco explorado, no campo da sociologia cultural. (LÖWY, 1989, p. 18).

Do ponto de vista da superação da divisão do trabalho na escola e conforme apresenta Rezzaghi (2009), as transformações no ensino ocorridas durante a experiência chinesa da revolução cultural foram incentivadas pela necessidade de se avançar na transição socialista. Durante o período, a tarefa fundamental dos novos planos pedagógicos era construir o homem novo, superar o ensino burguês, atingir as massas e fortalecer a ideologia proletária. Outro aspecto importante, segundo a autora, é a "revolucionarização das relações de produção". Esse foi o objetivo central da experiência chinesa da revolução cultural e visava levar a sociedade comunista à superação da divisão entre trabalho manual e intelectual por meio das mudanças na divisão do trabalho na escola.

Para compreendermos alguns aspectos da experiência chinesa da revolução cultural utilizaremos Naves (2005) e Bettelheim (1979). Para Naves (2005), o significado da experiência chinesa da revolução cultural reside em um verdadeiro retorno à inspiração originária de Marx. Ainda segundo Naves (2005, p. 101), não é suficiente para a ultrapassagem do capitalismo a simples transferência da titularidade dos meios de produção da burguesia privada para o Estado, porque o capital não é uma relação jurídica, nem uma relação de propriedade, mas uma relação social de produção, de modo que o seu fim depende da cessação do processo de valorização. Segundo o autor, para que isso possa

\begin{tabular}{|c|c|c|c|c|}
\hline Q Ronista Dialectus & Ano 2 & n. 6 & Janeiro - Agosto 2015 & p. $163-176$ \\
\hline
\end{tabular}


ocorrer é necessário que os trabalhadores tenham o controle efetivo do processo de produção, isto é, que eles não mais estejam separados dos meios de produção, o que significa superar a divisão entre o trabalho manual e o trabalho intelectual e superar a divisão entre as tarefas de direção e as tarefas de execução no processo de trabalho, permitindo-lhes a reapropriação das condições objetivas e subjetivas da produção.

Um dos resultados deste processo, segundo Bettelheim (1979), foi a constituição dos grupos intitulados de "tripla união". Esses grupos foram encarregados de questões técnicas, e eram constituídos por operários, técnicos e quadros. Segundo relato do autor, os operários constituíam o arcabouço desses grupos e a sua principal força. Os grupos de "tripla união" ocupam-se da transformação técnica das fábricas, da renovação técnica, das inovações e das modificações na regulamentação técnica, e da luta contra os "regulamentos irracionais" que existiam nesses domínios. Esses "regulamentos irracionais" permitiam aos engenheiros e técnicos unicamente o privilégio de gerenciar a produção.

Graças à formação desses grupos de tripla união, como também à educação política e ideologia e à participação de engenheiros e técnicos no trabalho manual, a separação entre os engenheiros e técnicos de um lado, e o operário do outro, tende a desparecer assim como a dominação dos primeiros sobre os segundos. Esse movimento é reforçado pela profunda transformação do sistema de ensino. (BETTELHEIM, 1979, p. 104).

A ideia de se utilizar "experiências na educação comparada" surgiu da constatação de que tais experiências possibilitam o desenvolvimento dos estudos sobre a "pedagogia do trabalho" (Cf. ROSSI, 1982; FARIAS, 1994 e VILELLA, 2009). Segundo nosso ponto de vista, a recuperação de tais experiências na educação permitiria compreender os desafios da formação de crianças, jovens, adultos e idosos em países que são "grandes sertões" (Cf. VILELLA, 2011a). Esta perspectiva implica em um enfoque coletivo dos problemas para lograr soluções em função de grandes coletivos humanos, para além das soluções ligeiras em educação, para além da "educação para o consenso" (Cf. FALLEIROS, 2005). Sobre essa temática, trataremos a seguir.

\section{ASPECTOS PRÁTICOS DA FORMAÇÃO DE PROFESSORES}

O trabalho apresentado em Vilella (2011a) procurou colocar em evidência o projeto blog de aula - mutirão de sociologia. O blog de aula (www.mutiraodesociologia.com.br) foi desenvolvido (como descrito em 2011b) como recurso didático e ferramenta no ensino de sociologia para os alunos do curso de pedagogia da Unesp de São José do Rio Preto (SP), doravante Rio Preto, e estendido, posteriormente, para escolas que manifestaram interesse em desenvolver tópicos da área de Ciências Humanas e suas Tecnologias. $\mathrm{O}$ projeto utiliza a metodologia de blog, um website frequentemente atualizado, no qual os conteúdos aparecem em ordem cronológica inversa. Podem conter textos, imagens, áudios, vídeos e animações. Esta metodologia possibilita a disseminação do conhecimento produzido pela universidade na internet, gratuitamente. A comunidade se relaciona através dos conteúdos possibilitando a transmissão de informações, fazendo da web um espaço de leitura, escrita, participação e reflexão.

\begin{tabular}{|l|l|l|l|l|}
\hline Gonista Dialectus & Ano 2 & n. 6 & Janeiro - Agosto 2015 & p. 163-176 \\
\hline
\end{tabular}


Enquanto recurso didático e ferramenta no ensino de sociologia, o blog possibilita a troca de ideias, definida pela participação e aportes dos usuários mediante comentários a distintos artigos e conteúdos, fomentando debate, discussão e uso responsável da web. A vertente interativa é uma das mais atrativas do ponto de vista educativo, sobretudo, pela visão mediadora da aprendizagem. Incentiva o trabalho cooperativo, através da gestão compartilhada do blog de aula. Isto unido à possibilidade de acesso de qualquer lugar, e a qualquer hora, abre grandes possibilidades de trabalho cooperativo. Qualquer pessoa em qualquer momento e lugar pode colaborar postando textos no blog. Os blogs de aula podem ser uma excelente ferramenta de apoio a projetos coletivos, diário de trabalho e caderno de aula digital. Os blogs são parte de um "hábitat" ou "ecossistema" da web, com usos e costumes relacionados entre si. Os blogs, unidos a outros aplicativos e serviços, multiplicam seu potencial ao adicionar conteúdo multimídia, marcadores sociais, ou etiquetas (tags) que são lidas e indexadas por outros aplicativos. Esse componente de socialização da web pode ser aproveitado tanto pelos alunos como pelos docentes.

O blog de aula "Mutirão de Sociologia" foi utilizado como uma ferramenta no Projeto Unesp de Educação de Jovens e Adultos, doravante Peja - Rio Preto. O Peja, um projeto institucional da Pró-Reitoria de Extensão Universitária, é desenvolvido nos campi da Universidade Estadual Paulista "Júlio de Mesquita Filho" (doravante, Unesp) que possuem cursos de graduação em Letras e/ou Pedagogia. Trata-se de uma contribuição da Unesp para minimizar a enorme dívida social do analfabetismo no contexto brasileiro para a formulação de metodologias alternativas em Educação de Jovens e Adultos (EJA) e para a discussão de políticas públicas nessa área do conhecimento. Um dos trabalhos do Peja Rio Preto foi desenvolvido no Centro de Convivência do Idoso, doravante CCI. No Peja Rio Preto do CCI, o foco central foi o desenvolvimento de práticas de letramento/escrita em contexto da tecnologia digital (Cf. Komesu; Tenani, 2010). Nesse sentido, os jovens, adultos e idosos puderam adquirir conhecimentos básicos de informática (word, internet, facebook, blogs, etc.) (1).

Além do desenvolvimento de práticas de letramento/escrita em contexto da tecnologia digital, os objetivos do Peja - Unesp para com os alunos atendidos são os de levá-los a: ler e escrever na Língua Materna (LM); empregar, com discernimento, o sistema de numeração decimal e as operações fundamentais na resolução de problemas do dia-a-dia; conhecer os direitos, deveres e leis que regem o mundo do trabalho; desenvolver noções de saúde física, psicológica e mental; discutir questões relativas à preservação do meio ambiente.

O espaço dos CCIs, conforme a SDS-SP (2004), tem por objetivo atender o idoso em situação de exclusão ou risco social, estimulando a inter-relação e o convívio social, o respeito à individualidade, à autonomia e à independência, fortalecendo os laços familiares, em uma perspectiva de prevenção ao asilamento. Os CCIs constituem um espaço destinado à permanência diurna onde são desenvolvidas diversas atividades para elevar o nível de qualidade de vida, de participação e de convivência social do idoso, promovendo trabalhos manuais (artesanais, decorativos, fabricação de objetos diversos) e vários tipos de atividades como: atividades físicas (ioga, tai chi chuan, alongamento, caminhadas, danças de salão, esportes), recreativas (jogos de salão, gincanas, passeios culturais, excursões, jogos ao ar livre), culturais (desenho, pintura, folclore, teatro, música instrumental, coral, expressão corporal, produção literária), associativas (trabalho voluntário, gerenciamento do trabalho, participações em associações e conselhos municipais etc.) e educacionais (escola aberta, palestras, filmes, vídeos, cursos rápidos, seminários, oficinas temáticas etc.). Os

\begin{tabular}{|l|l|l|l|l|}
\hline Govista Dialectus & Ano 2 & n. 6 & Janeiro - Agosto 2015 & p. 163-176 \\
\hline
\end{tabular}


CCIs incluem ainda diversos serviços: social, psicológico, médico, terapia ocupacional, nutrição/alimentação, fornecimento de remédios, jurídico, fisioterápico e estímulo ao desenvolvimento de ações que visem a autossustentação dos próprios CCIs.

O trabalho do Peja - Rio Preto no CCI configura-se como uma parceria entre a Unesp e a Secretaria Municipal de Assistência Social de Rio Preto (2) e tem por objetivos gerais inserir a população da terceira idade (3) no processo de inclusão digital, considerando as necessidades impostas por uma sociedade tecnológica. Para tal finalidade foi utilizado, entre outras ferramentas, o blog de aula - mutirão de sociologia (Cf. VILELLA, 2011b).

A forma como são escolhidos e trabalhados os conteúdos do blog de aula foram abordados em outros trabalhos, conferir VILELLA (2012) e (2011a). As atividades desenvolvidas têm em perspectiva a didática para a pedagogia histórico-crítica desenvolvida por Gasparin (2013) e elaborada a partir de Saviani (1999). Destaco, a seguir, a atividade realizada no CCI em 2013, cujo tema foi: "Brincar e ser criança no agora e no passado", descrita em: Vilella; Tenani; Silva (2014). O objetivo dessa atividade foi refletir sobre a noção de identidade na relação tempo/espaço, delimitando como objeto de reflexão a vivência da infância no passado e no futuro. A atividade possuía as seguintes questões para reflexão: "houve uma mudança da vivência da infância com o desenvolvimento tecnológico?; quais as principais diferenças que identificam que o desenvolvimento tecnológico gerou em relação ao lúdico na infância (brinquedos, brincadeiras, etc.)?”. Para a motivação das reflexões, as bolsistas do Peja - Rio Preto apresentaram o poema "Infância" do livro "Alguma Poesia" de Carlos Drummond de Andrade, e conduziram as rodas de conversas por meio da leitura coletiva do texto. Logo em seguida à leitura, ensinaram como acessar o link para que ouvissem a leitura do poema pelo próprio autor (Cf. Andrade, [1930] 2014).

O passo seguinte foi ler trechos do livro: "Quando eu era pequena", de Adélia Prado (Prado, 2006). As bolsistas estimularam os educandos a falar sobre as lembranças do período de suas infâncias, discutir sobre as tecnologias existentes no passado (período da infância dos hoje adultos e idosos). As impressões foram registradas em editor de texto Word pelos participantes. Os educandos foram fortemente encorajados a pesquisar imagens e links para complementar os textos por eles produzidos. Para a pesquisa de imagens e links, os bolsistas explicaram como fazer pesquisa em meios eletrônicos com navegadores. Foi utilizada também apresentação em power-point cujo intuito foi o de apresentar e, também, o de, posteriormente, ensiná-los a utilizar as ferramentas de apresentação de slides. Ficou combinado de os educandos fazerem um trabalho em powerpoint para a apresentação das principais impressões sobre as aulas, explicitando aspectos de que mais gostaram, possibilitando, inclusive, a prática de pesquisa e uso de links sobre os temas discutidos nas aulas.

Após essa etapa os alunos foram convidados a acessar o blog de aula - mutirão de sociologia (Cf. VILELLA, 2011b). Na categoria "Educoop" do blog os educandos encontraram o link: "Atividade do CCI - PEJA - UNESP - SJRP" com o seguinte texto instrucional: "Nesta atividade, escreva um pequeno texto sobre como eram as brincadeiras e os brinquedos na sua infância. Não se esqueça de contar os detalhes para que as crianças de hoje possam entender as brincadeiras e perceber como eram divertidos os brinquedos antigos. Você pode, também, explicar como era sua brincadeira favorita ou contar a história de um brinquedo de que gostava muito. Use links de imagens ou de vídeos,

\begin{tabular}{|c|c|c|c|c|}
\hline Q Ronista Dialectus & Ano 2 & n. 6 & Janeiro - Agosto 2015 & p. $163-176$ \\
\hline
\end{tabular}


disponíveis na internet, para ilustrar o texto" (Cf. VILELLA, 2013). A seguir, destaco a escrita da aluna Isilda (2013):

Há muitos anos, quando ainda a maioria destes jovens de hoje ainda nem eram nascidos, a vida simples no campo predominava. Estudava-se quando muito até o nível primário, somente então algumas famílias, o que era muito raro na época, conseguiam com bastante sacrifício enviarem seus filhos para a cidade mais próxima, o que lhes proporcionava oportunidade para prosseguir nos estudos. Provavelmente devido a esta dificuldade, via-se num futuro bem próximo o progresso daquele aluninho de origem caipira, que com o apoio dos familiares, em pouco tempo galgavam posições de destaque na sociedade, tornando-se para o orgulho de todos um grande profissional nos ramos diversos: na medicina, engenharia, educação, etc.

Quando já formados, integrados na vida urbana, lembravam com saudades dos tempos de criança, da vida na roça, onde havia galo, noites e quintais. Reviviam os dias na fazenda junto aos pais, aos vizinhos e parentes, todos com um estilo de vida semelhante, aos quais, a todos devíamos respeito e obediência. Às vezes antes de dormir, em noites enluaradas e de céu de um profundo azul e salpicado de estrelas, nós ainda crianças disputávamos o colo de um adulto, para que nesse aconchego familiar pudéssemos ouvir suas falas, suas estórias, seus poucos planos para o futuro. Tudo isso acontecia numa união que de tão densa, aparentava até o que nós adultos hoje chamamos de 'paraíso'... que ao nosso entender seria já um pedacinho do céu... cenas que desfilarão em nossas mentes como doces lembranças, de um tempo que não volta nunca mais. Foi nesse ambiente que eu e meus irmãos nascemos e crescemos, nos divertindo com brincadeiras geralmente improvisadas, pega-pega, barata, esconde-esconde, corda e outras... E sob o efeito dessa educação que crescemos, motivo pelo qual muitas vezes estranhamos o comportamento das crianças e jovens de hoje. (ISILDA, 2013).

No sentido de enfeixar essas duas seções e seguir para as considerações finais, o que fizemos foi evidenciar como se dá a articulação entre algumas propostas teóricas e práticas da formação de professores levando ao desenvolvimento de práticas letradas em contexto da tecnologia digital dos educandos do CCI, exemplificado através da aluna Isilda. Para além de um relato de experiência de formação de professores, o texto proporciona também uma reflexão sobre como o Peja - Rio Preto articula as propostas teóricas e práticas às demandas sociais de infoinclusão, promovendo a inclusão digital dos idosos e a experiência do pedagogo em formação na elaboração de atividades que atendam a essa população. O texto da aluna Isilda nos remete a noção de "ruralidade". Conforme aponta Wanderley e Fávaro (2013, p. 415), essa noção permite explicar a relação que as pessoas mantêm com o seu mundo rural, projetando sobre ele suas próprias características, processos evolutivos e valores. Cabe destacar, que temos desenvolvido estudos sobre essas "ruralidades" (Cf. VILELLA, 2013-2015 e VVILELLA; COSTA, 2013). Nesse sentido, acreditamos aprofundar algumas questões, quais sejam: a formação de professores, as possibilidades de superação da divisão do trabalho na escola através do trabalho coletivo, a gestão democrática na escola, especialmente na Educação de Jovens, Adultos e Idosos, tendo como cenário os usos das novas tecnologias aplicadas à educação.

\begin{tabular}{|l|l|l|l|l|}
\hline Q & Dovista \\
\hline
\end{tabular}




\section{CONSIDERAÇÕES FINAIS}

A proposta de utilizar "experiências na educação comparada", as novas tecnologias aliadas ao conceito de inteligência coletiva, possibilita vislumbrar soluções que visam superar a divisão entre o trabalho manual e o trabalho intelectual e tem importância para o desenvolvimento da crítica da divisão do trabalho na escola. Isso significa que uma das características mais profundas da sociedade dividida em classes, a saber, a separação social da teoria e da prática, está sendo retrabalhada. Na sociedade contemporânea essa separação é especialmente concretizada pela acumulação de conhecimentos teóricos científicos e técnicos, de um lado, e de conhecimentos "práticos" de outro. Os primeiros tomam a forma das ciências e técnicas das quais os "especialistas" são tidos como detentores exclusivos, enquanto que os conhecimentos "práticos" são reduzidos a simples detalhes ou habilidades manuais, mais ou menos rotineiras, desenvolvidas pelos "professores". Segundo nosso ponto de vista, a recuperação de experiências na educação permite trabalhar a organização de conteúdos de maneira a superar a divisão do trabalho na escola. Ao elaborarmos a crítica à divisão do trabalho na escola, consolida-se uma gestão democrática da escola. As práticas educativas desenvolvidas no CCI de Rio Preto refletem essa perspectiva.

Uma das questões centrais das práticas educativas, conforme apresentada por Zabala (1999 e 1998), que está sendo reelaborada,é a formação de novos valores e atitudes em âmbito individual e coletivo e da valorização da escola como espaço privilegiado, embora não o único, de formação de crianças e jovens. Formação do homem concebido como ser natural e objetivo, que se autocria e se forma no decorrer da história mediante a atividade de objetivação-apropriação, mecanismo que assegura a "mediação" entre o indivíduo e a história da humanidade, e que "humaniza os sentidos do homem, forma a subjetividade histórica e social”. (Cf. Duarte, 1993).

A tentativa deste trabalho é consolidar uma escola diferenciada e de qualidade, protagonizada e gerida pelos próprios sujeitos, a partir da formação de professores e do estabelecimento de um currículo diferenciado. Os participantes do projeto, ao longo do período de sua formação, têm a oportunidade de receber uma formação específica, mantendo um diálogo constante com as escolas e capacitando-se para desenvolver uma relação de ensino-aprendizagem em uma perspectiva diferenciada. Esses participantes ajudam na formação escolar dos educandos, através de uma visão crítica da sociedade envolvente, procurando contribuir com subsídios para que exerçam seus direitos de cidadania.

\section{REFERÊNCIAS}

ANDRADE, Carlos. D. Infância. In: Alguma poesia. 1930. Net, São Paulo, 2014. Disponível em: < http://letras.mus.br/carlos-drummond-de-andrade/460647/ >. Acesso em: 12 jun. 2014.

ANTUNES, Ricardo. Adeus ao trabalho? Ensaio sobre as metamorfoses e a centralidade do mundo do trabalho. 12. ed. Campinas: Cortez; UNICAMP, 2007.

\begin{tabular}{|l|l|l|l|l|}
\hline Govista Dialectus & Ano 2 & n. 6 & Janeiro - Agosto 2015 & p. 163-176 \\
\hline
\end{tabular}


APPLE, Michael W. Trabalho docente e textos: economia política das relações de classe e de gênero em educação. Porto Alegre: Artes Médicas, 1995.

BARBOSA, Sandra J. A intensificação do trabalho docente na escola pública. 2009. 168p. Dissertação (Mestrado em Educação). Faculdade de Educação, Universidade de Brasília.

BETTELHEIM, Charles. Revolução cultural e organização industrial na China. Rio de Janeiro: Graal, 1979.

BRUNO, Lúcia. Poder e administração no capitalismo contemporâneo. In: OLIVEIRA, Dalila A. (Org.). Gestão democrática da educação: desafios contemporâneos. 6. ed. Petrópolis: Vozes, 2005.

CARVALHO, Olgamir F. de. A escola como mercado de trabalho: os bastidores da divisão do trabalho no âmbito escolar. São Paulo: Iglu, 1989.

CURY, Carlos R. J. Educação e contradição: elementos metodológicos para uma teoria crítica do fenômeno educativo. 6. ed. São Paulo: Cortez, 1995.

DAL ROSSO, Sadi; FORTES, José A. A. S. (Orgs.). Condições de trabalho no limiar do século XXI. Brasília: Épocca, 2008.

DUARTE, Newton. A individualidade para si: contribuição a uma teoria histórico-social da formação do indivíduo. Campinas: Autores Associados. 1993.

ENGUITA, Mariano F. A Aprendizagem das relações sociais de produção. In: Trabalho, escola e ideologia: Marx e a crítica da educação. Porto Alegre: Artes Médicas, 1993. p. $208-258$

ESTEVE, José M. O mal-estar docente: a sala de aula e a saúde dos professores. Bauru: EDUSC, 1999.

FARIAS, Itamar Mazza de. Pedagogia do trabalho: seus princípios no cotidiano escolar. Campinas: 1994. 193p. Tese (Doutorado em Educação). Universidade Estadual de Campinas.

FALLEIROS, Ialê. Parâmetros curriculares nacionais para a educação básica e a construção de uma nova cidadania. In: NEVES, L. M. W. (Org.). A nova pedagogia da hegemonia: estratégias do capital para educar o consenso. São Paulo: Xamã, 2005.

GASPARIN, João L. Uma didática para a pedagogia histórico-crítica. 5. ed. Revista. Campinas: Autores Associados, 2013.

GRAMSCI, Antonio. Escritos políticos. v. 2. A questão meridional. Organização e tradução de Carlos Nelson Coutinho. Rio de Janeiro: Civilização Brasileira, 2004.

Cadernos do cárcere. v. 2. Os intelectuais. O princípio educativo. Jornalismo. Tradução Carlos Nelson Coutinho. Rio de Janeiro: Civilização Brasileira, 2000.

FREITAS, Luís C. Crítica da organização do trabalho pedagógico e da didática. 11. ed. Campinas: Papirus, 2011.

GOLDMANN, Lucien. Les sciences humaines et la philosophie. Paris: Denoel, 1966.

\begin{tabular}{|l|l|l|l|l|}
\hline Govista Dialectus & Ano 2 & n. 6 & Janeiro - Agosto 2015 & p. 163-176 \\
\hline
\end{tabular}


GORZ, André et al. Crítica da divisão do trabalho. 3. ed. São Paulo: Martins Fontes, 1996.

HIRATA, Helena. (Org.). Divisão capitalista do trabalho. Tempo Social, Rev. Sociol. USP, S. Paulo, 1 (2): 73-103, 2. Sem. 1989.

HYPOLITO, Álvaro M. Trabalho docente, classe social e relações de gênero. Campinas: Papirus, 1997.

JÁEN, Marta J. Os docentes e a racionalização do trabalho em educação: elementos para uma crítica da teoria da proletarização dos docentes. Teoria \& Educação. Porto Alegre, n. 4, 1991, p. 74-89.

KOMESU, Fabiana C.; TENANI, Luciani E. Práticas de letramento/escrita em contexto da tecnologia digital. Eutomia (Recife), v. 1, p. 1-15, 2010.

KORSCH, Karl. Marxisme et philosophie. Paris: Minuit, 1964.

LIMA, Licínio C. Participação e não-participação na escola. In: Participação e nãoparticipação na escola. A escola como organização educativa: uma abordagem sociológica. São Paulo: Cortez, 2001.

LÖWY, Michael. As aventuras de Karl Marx contra o Barão de Münchhausen: marxismo e positivismo na sociologia do conhecimento. 9. ed. rev. e ampl. São Paulo: Cortez, 2009.

Redenção e utopia: o judaísmo libertário na Europa Central. São Paulo: Companhia das Letras, 1989.

LUKÁCS, György. Histoire et consciente de classe. Paris: Minuit, [1923 (1960)].

MACCIOCCHI, Maria-Antonietta. A favor de Gramsci. 2. ed. Rio de Janeiro: Paz e Terra, 1977.

MACHADO, Ilma F. Educação solidária e formação omnilateral. In: ZART, Laudemir Luiz. (Org.). Educação e sócio-economia solidária: paradigmas de conhecimento e de sociedade. Cáceres: Unemat Editora, 2004, v. 1, p. 96-104.

MÉSZÁROS, István. Divisão do trabalho e Estado pós-capitalista. In: Para além do capital: rumo a uma teoria da transição. São Paulo: Boitempo, 2002. p. 1032-1062.

WANDERLEY, Maria de N. B.; FAVARETO, A. A singularidade do rural brasileiro: implicações para as tipologias territoriais e a elaboração de políticas públicas. In: MIRANDA, C.; SILVA, H. (Org.). Concepções da ruralidade contemporânea: as singularidades brasileiras. Brasília: IICA, 2013. (Série Desenvolvimento Rural Sustentável; v. 21). p. 413-473.

NAVES, Márcio B. Mao: o processo da revolução. São Paulo: Brasiliense, 2005.

OLIVEIRA, Dalila A. A reestruturação do trabalho docente: precarização e flexibilização. Educação e Sociedade, Campinas, v. 25, n. 89, 2004.

PORTELLI, Hugues. Gramsci e o bloco histórico. 5. ed. Tradução Angelina Peralva. Rio de Janeiro: Paz e Terra, 1990.

\begin{tabular}{|l|l|l|l|l|}
\hline Govista Dialectus & Ano 2 & n. 6 & Janeiro - Agosto 2015 & p. 163-176 \\
\hline
\end{tabular}


PRADO, Adélia. Quando eu era pequena. São Paulo: Record, 2006.

REZZAGHI, Mariana D. B. A educação no período de transição socialista: a experiência chinesa da revolução cultural e as mudanças no ensino e nas relações de produção. 2009. 125p. Dissertação (Mestrado em Sociologia). Programa de Pós-graduação em Sociologia, Instituto de Filosofia e Ciências Humanas, Universidade Estadual de Campinas, 2009.

ROSSI, Wagner G. Pedagogia do trabalho 2: caminhos da educação socialista. São Paulo: Moraes, 1982.

SAVIANI, Dermeval. Escola e democracia. 32. ed. Campinas: Autores Associados, 1999.

SDS-SP. Centro de Convivência do Idoso. Portal da Secretaria de Estado de Desenvolvimento Social do Estado de São Paulo. Net, São Paulo, 2004. Disponível em: < http://www.desenvolvimentosocial.sp.gov.br/ >. Acesso em 12 jun. 2014.

SILVA, Luís G. A. As mudanças na gestão e organização da escola: a participação como estratégia de reforma. Linhas Críticas, Brasília, vol.11, n. 21. p. 265-282, jul./dez. 2005.

TORRES SANTOMÉ, Jurjo. A educação em tempos de neoliberalismo. Porto Alegre: Artmed, 2003.

VILELLA, F. F.. Novas ruralidades e mundo do trabalho: estudo das representações sociais de jovens de escolas de meio rural através do uso de mídias sociais. 2013-2015. (Projeto de Pesquisa do Plano Global de Atividades). Departamento de Educação, Instituto de Biociências, Letras e Ciências Exatas, Universidade Estadual Paulista, São José do Rio Preto.

Mutirão de sociologia - blog de aula. (Projeto de Extensão). Atividade do CCI -

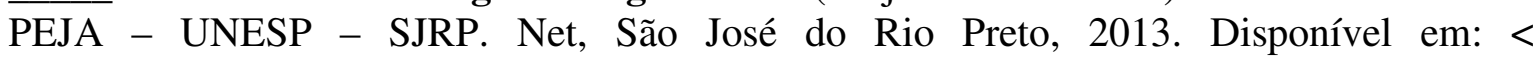
http://www.mutiraodesociologia.com.br/?p=1930 >. Acesso em: 12 jun. 2014.

Intelectuais e divisão do trabalho na escola: apontamentos para uma gestão democrática do ensino médio. In: Seminário Internacional 90 Anos do Movimento Comunista no Brasil, 2012, Marília - SP. Anais do Seminário Internacional 90 Anos do Movimento Comunista no Brasil. Marília - SP: Unesp, 2012. v.1. p.1 - 16

Novas tecnologias, inteligência coletiva e educação: o blog de aula - mutirão de sociologia In: $\mathbf{1 0}^{\circ}$ Jornada do Núcleo de Ensino de Marília, 2011a, Marília - SP. Anais da $10^{\circ}$ Jornada do Núcleo de Ensino de Marília. Marília - SP: Oficina Universitária, 2011a. v. 1. p. 1 - 15 .

. Mutirão de sociologia - blog de aula. (Projeto de Extensão). Um filme rodado no distrito de Talhado de São José do Rio Preto - SP - Brasil: João de Barro de Raffaele Rossi (1970). Net, São José do Rio Preto, 2011b. Disponível em < http://www.mutiraodesociologia.com.br/?p=841 >. Acesso em: 12 jun. 2014.

A formação de intelectuais e a organização do trabalho pedagógico. 2010-2012. (Projeto de Pesquisa do Plano Global de Atividades). Departamento de Educação, Instituto de Biociências, Letras e Ciências Exatas, Universidade Estadual Paulista, São José do Rio Preto.

\begin{tabular}{|l|l|l|l|l|}
\hline Govista Dialectus & Ano 2 & n. 6 & Janeiro - Agosto 2015 & p. 163-176 \\
\hline
\end{tabular}


A escola da justiça global. 2009. Supervisão: Prof ${ }^{a}$. Dra ${ }^{a}$. Liliana Rolfsen Petrilli Segnini. Monografia (Pós-Doutorado). Faculdade de Educação, Universidade Estadual de Campinas.

.; COSTA, F. S. Os caipiras e suas representações: estudo sobre o preconceito contra a origem geográfica e de lugar em jovens de escolas de meio rural para a formação de professores em educação do campo In: II Seminário Nacional de Estudos e Pesquisas sobre Educação do Campo e IV Jornada de Educação Especial no Campo, 2013, São Carlos - SP. Anais do II Seminário Nacional de Estudos e Pesquisas sobre Educação do Campo e IV Jornada de Educação Especial no Campo. São Carlos - SP: Editora da Ufscar, 2013. v.1. p. $1-15$

.; TENANI, L. E.; SILVA, C. L. F. da. O Programa Unesp de Educação de Jovens e Adultos. In: AZEREDO-OLIVEIRA, M. T. V. de. Livro de resumos dos projetos de extensão do câmpus de São José do Rio Preto (UNESP/IBILCE). São José do Rio Preto: UNESP - Câmpus de São José do Rio Preto, 2014.

ZABALA, Antoni (Org.). Como trabalhar os conteúdos procedimentais em aula. 2. ed. Porto Alegre: Artes Médicas, 1999.

ZABALA, Antoni. A prática educativa: como ensinar. Porto Alegre: Artes Médicas, 1998.

NOTAS

(1) Para o desenvolvimento das temáticas relacionadas ao internetês, o projeto contou com a colaboração das professoras Dras. Fabiana Komesu e Luciani Tenani, ambas do Departamento de Estudos Linguísticos e Literários.

(2) Essa parceria foi firmada por meio de "termo aditivo" ao convênio em vigor entre a Unesp e a Prefeitura Municipal de Rio Preto, desenvolvido por meio da equipe do Peja Rio Preto, a partir de 2013.

(3) A população é cadastrada no Centro de Referência da Assistência Social (CRASS) para ser selecionada para frequentar o CCI - Rio Preto, localizado na Av. Philadelpho Manoel Gouveia Neto, 785, Vila Novaes, zona norte da cidade.

\begin{tabular}{|l|l|l|l|l|}
\hline Q Rowita Dialectus & Ano 2 & n. 6 & Janeiro - Agosto 2015 & p. 163-176 \\
\hline
\end{tabular}

